\title{
Effectiveness of pulsed electromagnetic field therapy on pain, functional status, and quality of life in patients with chronic non-specific neck pain: A prospective, randomized-controlled study
}

\author{
Merve Karakaş@, Haydar Gök (1) \\ Department of Physical Medicine and Rehabilitation, Ankara University Faculty of Medicine, Ankara, Turkey \\ Received: August 23, 2019 Accepted: November 19, 2019 Published online: May 18, 2020
}

\begin{abstract}
Objectives: The aim of this study was to evaluate whether pulsed electromagnetic field (PEMF) therapy when applied in addition to a conventional physical therapy program would provide any further benefits in reducing pain and functional limitation in patients with chronic non-specific neck pain.

Patients and methods: This double-blind, prospective, randomized, placebo-controlled study included a total of 63 patients (15 males, 48 females; mean age 45.1; range, 25 to 59 years) with a complaint of mechanical neck pain between January 2016 and September 2016 . The patients were divided into two groups as PEMF therapy group $(n=33)$ and control group $(n=30)$. A total of 15 sessions of conventional physical therapy program were applied to both groups for a total of three weeks. In addition, the active group received 20-min PEMF and the control group received 20-min sham PEMF. The patients were evaluated at baseline and after treatment. The therapeutic effect was evaluated using the visual analog scale (VAS), Neck Pain Disability Scale (NPDS), Short Form-36 (SF-36), and Physician Global Assessment (PGA).

Results: At baseline, two groups were similar in terms of the demographic and clinical characteristics ( $>0.05$ ). There were significant improvements in the VAS, NPDS, SF-36, and physician global assessment after treatment in both groups. However, the PEMF group was not found to be superior to the sham group in terms of improvements in the outcome parameters.

Conclusion: Our study findings indicate that PEMF therapy is safe in patients with chronic non-specific neck pain. However, it does not provide further improvement in pain and functionality when applied in addition to a conventional physical therapy.
\end{abstract}

Keywords: Non-specific neck pain, physical therapy, pulsed electromagnetic field.

Neck pain is a common musculoskeletal complaint and has a significant impact on patients, family members, and healthcare systems, leading to significant disability ${ }^{[1]}$ It is the second most common musculoskeletal problem after low back pain with a point prevalence of 10 to $20 \%$ and a lifetime prevalence of 30 to $50 \% \cdot{ }^{[2,3]}$ Neck pain may resolve spontaneously within a few weeks or may become chronic in $30 \%$ of cases. ${ }^{[3]}$ There is a substantial variation in treatment approaches for chronic neck pain in clinical practice. ${ }^{[4]}$ These include education, ergonomics, analgesics, myorelaxants, and nonsteroidal antiinflammatory drugs (NSAIDs), transcutaneous electrical nerve stimulation (TENS), superficial and deep heating methods, manipulation, mobilization, nerve blockade, and surgical intervention. ${ }^{[5,6]}$

Pulsed electromagnetic field (PEMF) therapy is an easy, non-invasive, safe, and a relatively new treatment method which is used with growing interest in physical and rehabilitation medicine. Historically, the benefits from magnetotherapy has been reported for patients with musculoskeletal disorders, wounds, and pain. ${ }^{[7]}$ Currently, it is commonly used to help to alleviate pain.

The effectiveness of PEMF therapy in relief of pain due to fracture union, fibromyalgia syndrome, knee osteoarthritis, cervical fusion, cervical osteoarthritis, and cervical disc herniation have been investigated

Corresponding author: Haydar Gök, MD. Ankara Üniversitesi Tip Fakültesi Fiziksel Tıp ve Rehabilitasyon Anabilim Dalı, 06590 Çankaya, Ankara, Türkiye. e-mail: haydar.gok@gmail.com 
previously. ${ }^{[8-13]}$ However, there is no randomizedcontrolled study in the literature investigating its effectiveness in patients with chronic non-specific neck pain. In the present study, therefore, we aimed to evaluate whether the PEMF therapy is effective as an adjunct to conventional physical therapy in improving pain and functional status in patients with chronic non-specific neck pain.

\section{PATIENTS AND METHODS}

This double-blind, prospective, randomized, placebo-controlled study was conducted at Ankara University, Faculty of Medicine, Department of Physical \& Rehabilitation Medicine between January 2016 and September 2016. A total of 74 patients with mechanical neck pain were included. Inclusion criteria were as follows: having mechanical neck pain more than three months and less than two years, age between 25 and 60 years, having normal laboratory test results, absence of fracture, dislocation, tumor or infection on radiological investigation, pain severity of at least $4 / 10$ according to the visual analog scale (VAS), and willingness to sign the informed consent form. Exclusion criteria were as follows: pregnancy and breastfeeding, having a cardiac pacemaker implanted, metal implant or electronic device in any part of body, a prior trauma (whiplash), surgical or algological intervention in cervical area, history or suspicion of any malignancy, presence of inflammatory joint pain or diagnosis of a rheumatic disease, presence of an open superficial wound, presence of more severe pain in any part of body other than neck pain, an advanced stage mood disorder, a neurological disorder (multiple sclerosis, syringomyelia, or Parkinson's disease), radiographical Grade $\geq 2$ spondylolisthesis, spinal instability or advanced spondylarthrosis, physical therapy for neck pain within the last six months, a history of drug use other than paracetamol (NSAIDs, centrally acting and narcotic analgesics) or discontinuation of such drugs less than three months before the enrolment. A written informed consent was obtained from each patient. The study protocol was approved by the Ankara University, Faculty of Medicine, Ethics Committee (15/12/2015, No: 19-842-15) and Turkish Medicines and Medical Devices Agency (21/12/2015, No: 71146310). The study was conducted in accordance with the principles of the Declaration of Helsinki.

\section{Patient enrolment, randomization, concealment and blinding}

A total of 100 patients with chronic non-specific neck pain were screened for eligibility. Of these patients,
74 who met the inclusion criteria were randomized into two groups: the PEMF and sham. The block randomization was performed using the Random Allocation Software (RAS) computer program via a block size of four. The sealed envelope method was preferred to ensure concealment. The study was designed as a double-blind study in which physicians and patients were not aware of treatment allocation. All patients were evaluated by a single physician. All treatments were performed by a single physiotherapist. Both groups received hot pack, TENS, and homebased exercise program (i.e., cervical range of motion, stretching of cervical and dorsal extensor muscles, cervical isometric, relaxation and postural exercises) as the part of the conventional physical therapy. The PEMF group was additionally given PEMF therapy. The control group received sham PEMF therapy. The neck of the patient was placed on the PEMF device. An electromagnetic field was applied to cervical area for 20 min every weekday at an intensity of $50 \%$ and a frequency range of 10 to $100 \mathrm{~Hz}$ using ASV ${ }^{\mathrm{TM}}$ magnetotherapy device (ASA model PMT Quattro PRO-Italy) with a solenoid diameter of $80 \mathrm{~cm}$. All patients received a total of 15 sessions for a total of three weeks.

\section{Assessment}

The severity of neck pain was assessed using the VAS with scores between 0 and 10 on a $10-\mathrm{cm}$ horizontal line. The Neck Pain and Disability Scale (NPDS) was used for the assessment of disability. ${ }^{[14]}$ The Turkish version of the NPDS was found to be a valid and reliable method of measurement for evaluating disability, caused by problems of the neck region. ${ }^{[15]}$ The Short Form-36 (SF-36) was used for the evaluation of quality of life. ${ }^{[16]}$ The reliability and validity of the Turkish version of the SF-36 have been shown previously. ${ }^{[17]}$ The Patient Global Assessment (PGA) was used for overall assessment. The primary outcome variable was neck pain as assessed by VAS, and all assessments were repeated at the end of treatment.

\section{Statistical analysis}

The sample size was calculated using the power analysis considering neck pain before the study. A sample size of 63 would achieve $87 \%$ power with a significance level of 0.05 using a two-sided one sample t-test. Considering a dropout rate of $10 \%$, the sample size was increased to 74 .

Statistical analysis was performed using the R Statistical Program version 3.6.2 ( $R$ statistical software, Institute for Statistics and Mathematics, 


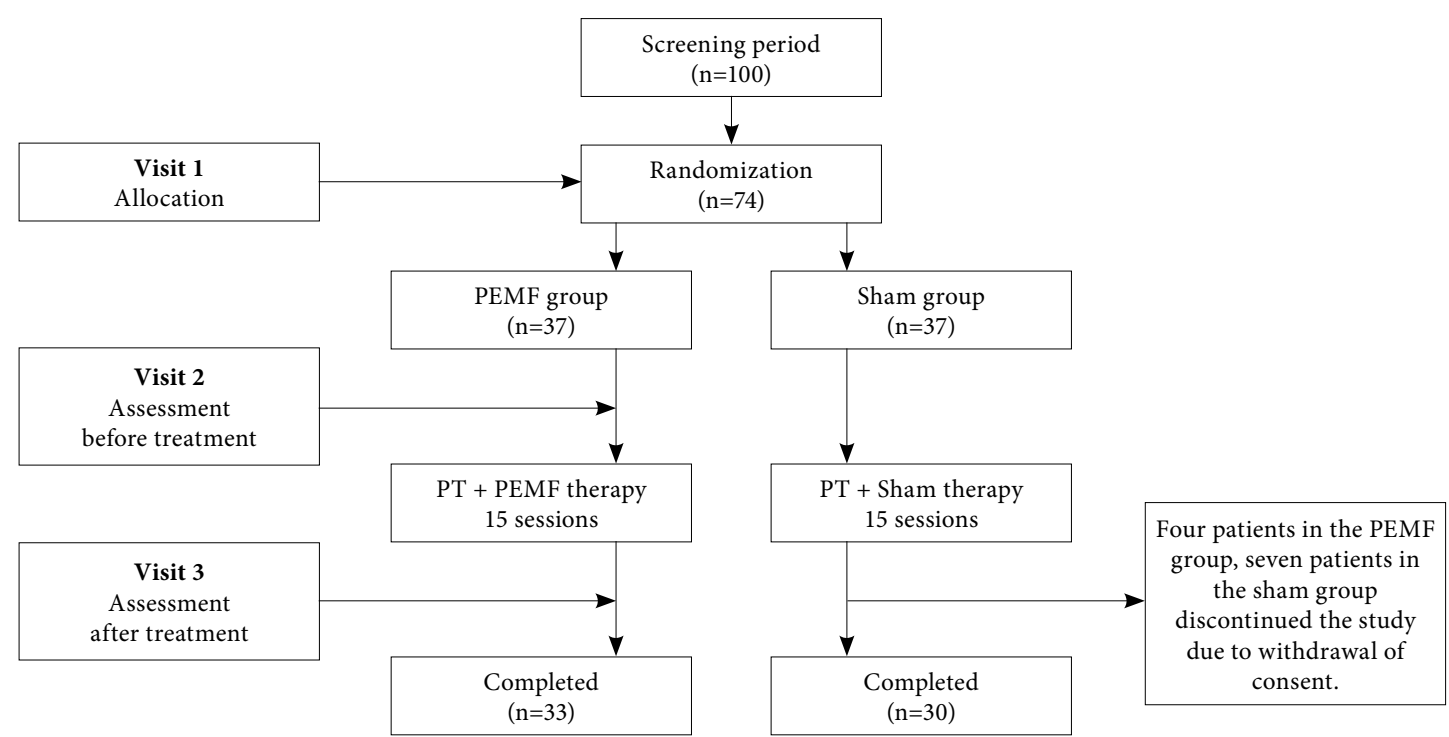

Figure 1. Study flowchart.

PEMF: Pulsed electromagnetic field; PT: Physical therapy.

Vienna, Austria). Continuous variables were expressed in mean \pm standard deviation (SD), or median (min-max), while categorical variables were expressed in number and frequency. The Kolmogorov-Smirnov test was used to evaluate the normal distribution of data. The two-way analysis of variance, Student's t-test, Mann-Whitney U test, and chi-square test were used for inter-group comparisons. Among all variables, only the NPDS showed normal distribution. Therefore, the twoway analysis of variance was calculated using the treatment group and time as factors and the NPDS as a dependent variable. The Wilcoxon signed-rank test was used for intra-group comparisons. A $p$ value of $<0.05$ was considered statistically significant.

\section{RESULTS}

Of a total of 74 patients who met the inclusion criteria, 11 discontinued the study due to withdrawal of consent. Finally, a total of 63 patients completed the trial of whom 33 were in the PEMF group and 30 were in the sham group (Figure 1). Of these patients, 15 were males and 48 were females with a mean age of 45.1 (range, 25 to 59 ) years. There were no significant differences in age and sex distribution between the groups $(\mathrm{p}=0.239$ and $\mathrm{p}=0.933$, respectively). The durations of symptoms were also similar between the groups $(\mathrm{p}=0.424)$ Baseline demographic and clinical characteristics of the patients are shown in Table 1.

After treatment, there was a significant reduction in neck pain in the PEMF and sham groups $(\mathrm{p}<0.001$ and $\mathrm{p}<0.001$ respectively) (Table 2 ). However, the intergroup comparison yielded no significant difference $(p=0.256)$. The two-way analysis of variance showed that there was no significant interaction between the group and time on the NPDS scores (Figure 2). The main effect of time showed a significant improvement in terms of neck pain-related disability as evidenced

\begin{tabular}{|c|c|c|c|c|c|c|c|c|c|}
\hline \multirow[b]{3}{*}{ Parameter } & \multirow{2}{*}{\multicolumn{4}{|c|}{$\begin{array}{l}\text { TABLE } 1 \\
\text { mographic and clinical character } \\
\text { PEMF group }(n=33)\end{array}$}} & \multirow{2}{*}{\multicolumn{4}{|c|}{ Sham group $(\mathrm{n}=30)$}} & \multirow[b]{3}{*}{$p$} \\
\hline & & & & & & & & & \\
\hline & \multirow[t]{2}{*}{$\mathrm{n}$} & \multirow{2}{*}{$\begin{array}{c}\text { Mean } \pm \text { SD } \\
43.9 \pm 7.8\end{array}$} & \multirow[t]{2}{*}{ Median } & \multirow[t]{2}{*}{ Min-Max } & \multirow[t]{2}{*}{$\mathrm{n}$} & \multirow{2}{*}{$\begin{array}{c}\text { Mean } \pm \text { SD } \\
46.3 \pm 8.2\end{array}$} & \multirow[t]{2}{*}{ Median } & \multirow[t]{2}{*}{ Min-Max } & \\
\hline Age (year) & & & & & & & & & 0.239 \\
\hline Sex & & & & & & & & & 0.933 \\
\hline Female & 25 & & & & 23 & & & & \\
\hline Male & 8 & & & & 7 & & & & \\
\hline Duration of symptoms (month) & & & 12 & $3-120$ & & & 13.5 & 3-75 & 0.424 \\
\hline
\end{tabular}




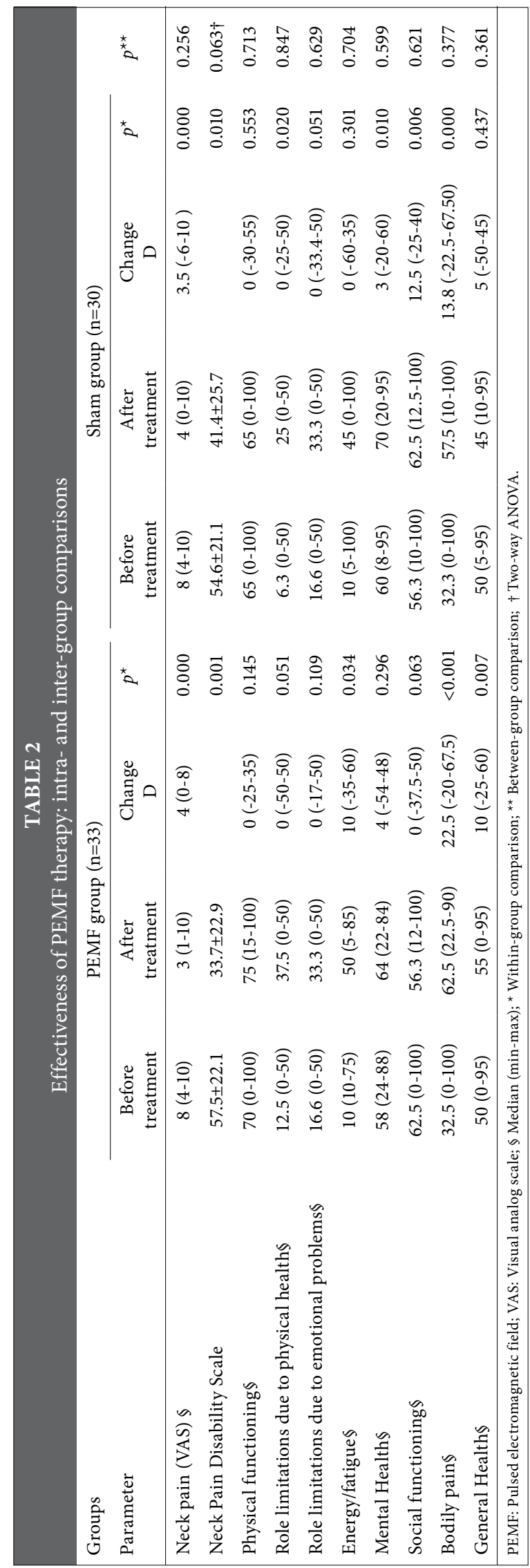

by changes in the NPDS scores $(p<0.001)$. The main effect of group showed no significant difference between the groups $(p=0.063)$. The improvements in the scores of mental health, social functioning, physical functioning, physical role difficulty, and emotional role difficulty did not reach a statistical significance.

There were also significant improvements in the PGA in the PEMF and sham groups after treatment. However, the PEMF group was not found to be superior to the sham group $(\mathrm{p}=0.389)$ (Table 3$)$.

\section{DISCUSSION}

The current study demonstrates that the addition of PEMF therapy to a conventional physical therapy program does not provide a superior efficacy in reduction of pain and functional limitation in patients with chronic non-specific neck pain. In the literature, there is no controlled study investigating the effectiveness of PEMF therapy in patients with chronic non-specific neck pain. The available limited research included patients with cervical osteoarthritis, fibromyalgia, vertebral fusion, and cervical disc herniation suffering from neck pain. ${ }^{[8,9,12,13]}$ Therefore, these controlled studies were to be the mainstay for comparison and discussion of the current findings.

Foley et al. ${ }^{[9]}$ reported that PEMF therapy was not superior to placebo with respect to the improvement

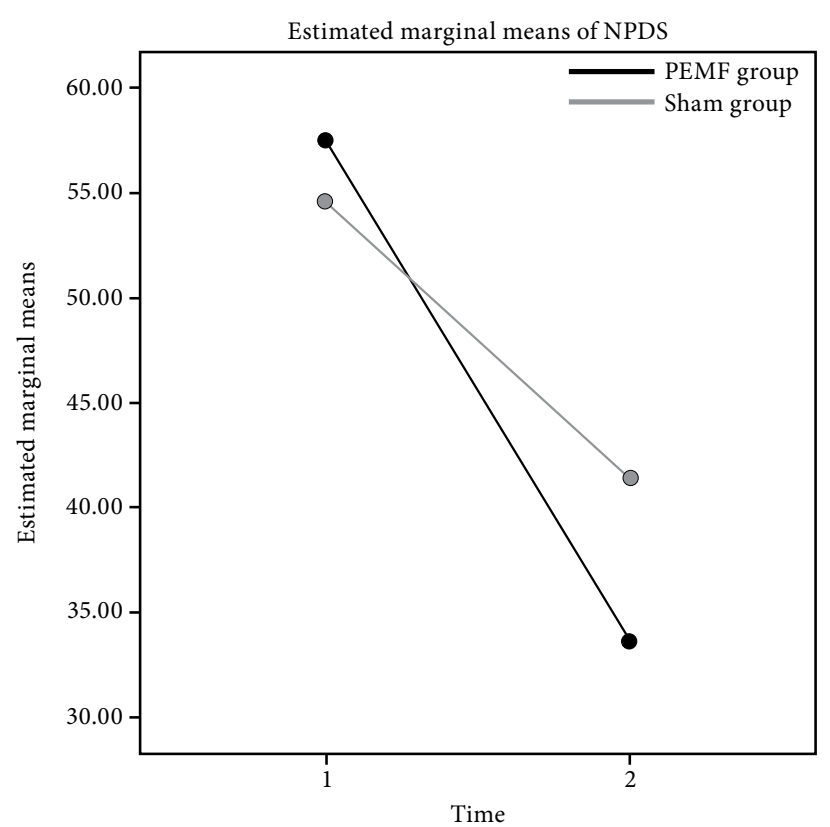

Figure 2. Interaction between the group and time on the NPDS scores (The two-way analysis of variance).

NPDS: Neck Pain and Disability Scale; PEMF: Pulsed electromagnetic field. 


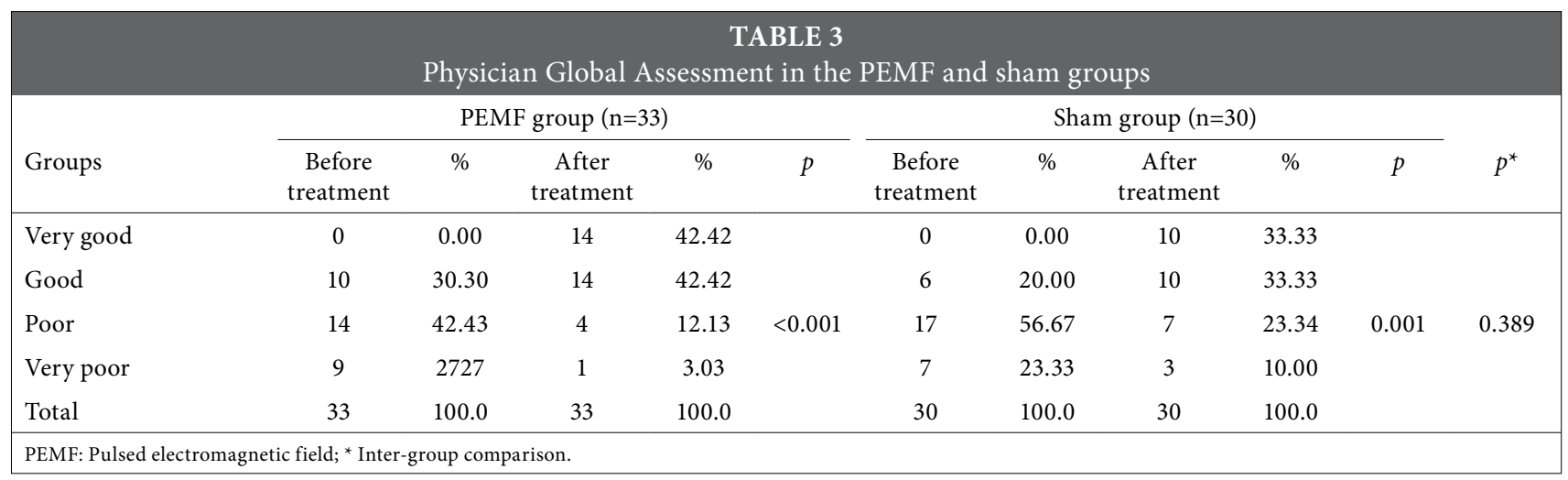

in VAS, NPDS, and SF-12 scores as determined by pre- and postoperative, 6 and 12-month assessments in patients with cervical fusion. Similarly, the current study failed to demonstrate the superiority of PEMF therapy over conventional physical therapy using the same parameters of VAS and NPDS. Additionally, PGA, a qualitative measure of treatment outcome commonly used in clinical practice, did not prove supporting evidence for efficacy of PEMF therapy. On the other hand, in a double-blind, randomized, sham-controlled study conducted in patients with cervical osteoarthritis, PEMF therapy was found to be superior to sham in all parameters assessed. ${ }^{[8]}$ The apparent discrepancy can be explained by several ways including the methodology of the study. The main discrepancy between the studies was the dose of electromagnetic field used. In the aforementioned study, the authors applied PEMF therapy twice a day for a total of $60 \mathrm{~min}$, while it was applied once a day for $20 \mathrm{~min}$ in our study. The marked and relatively lower dose in the current study might be the cause of the observed ineffectiveness. Nonetheless, there is no standardization for the dose of magnetotherapy in different disease conditions. One can also argue against the impracticability of applying therapy twice a day or unnecessarily long duration of therapy session. On the other hand, the lack of efficacy cannot be attributed to low power, since the sample size was determined with a priori power analysis. Another major difference in the methodology was that the patients were allowed to receive NSAIDs before and during treatment in the aforementioned study. Using magnetotherapy together with NSAIDs could have exaggerated the observed efficacy. Treatment, however, was initiated after a onemonth NSAID washout period in the current study.

In another study, Hattapoğlu et al., ${ }^{[13]}$ investigated the efficiency of PEMF therapy on pain, disability, psychological state, and quality of life in patients with cervical disc herniation. They were unable to demonstrate a significant improvement in any of the parameters at three weeks after treatment. At 12 weeks, the improvement was seen only in pain and sleep domain of the quality of life. These findings are consistent with that of the current study, as the duration and intensity of PEMF therapy were similar. However, the aforementioned authors did not calculate the sample size before the study, raising the possibility that the study was low powered. Nevertheless, this does not seem to be the case, as their sample size can be considered adequate in the light of the power analysis findings of the current study.

There is only one controlled experimental study in the literature which investigated the effectiveness of PEMF therapy in patients with fibromyalgia. ${ }^{[12]}$ Contrary to our study, the authors concluded that the a three-week PEMF therapy given to female patients aged between 18 and 60 years resulted in a significantly greater improvement in pain and quality of life, compared to sham therapy. However, this study had a washout period of two months for physical therapy, which was markedly shorter, compared to the current study (six months). Also, the sham group received no treatment in this trial.

Recently, a systematic review on effectiveness of PEMF therapy in patients with chronic neck pain evaluated 20 trials and concluded that there was no adequate evidence to draw a firm conclusion about the effectiveness and clinical benefit of magnetic field therapy on neck pain. ${ }^{[18]}$ This was attributed to the heterogeneity of treatment subtypes, protocol differences, and inadequacy of sample size in the trials.

The physiopathology of analgesic properties of PEMF therapy was not examined in the current study. It was previously reported that the magnetic field 
treatment ensured vasodilation, analgesic effects, antiinflammatory effects, acceleration of improvement and anti-edematous effects. ${ }^{[19]}$ The mechanism of action was usually demonstrated to be at cellular level, activating the enzymatic processes, metabolic transfers, and cell membrane functions. ${ }^{[11]}$ It was suggested that the endogenous opioid system and nitric oxide activity were responsible for the analgesic effect. ${ }^{[20]}$ Magnetotherapy has been reported to increase oxygen release from erythrocytes, thereby, ensuring tissue oxygenation, and to cause acceleration of the blood flow at the application area, vasodilation, and changes in blood ion content. ${ }^{[20]}$ This results in a decrease in toxins in damaged area and increases in vital nutrients and endorphins, reducing the nociceptor sensitivity.

There are no standard treatment protocols among studies assessing the effectiveness of PEMF. Different intensities of electromagnetic field were used in various trials. The PEMF intensity used in the current study was 85 Gauss with a frequency of $20 \mathrm{~Hz}$, while it was as $40 \mu \mathrm{T}$ with a frequency range of 0.1 to $64 \mathrm{~Hz}$ in another study, ${ }^{[8]} 5.6 \mathrm{mT}$ with a frequency of $10 \mathrm{~Hz}$ in another study, ${ }^{[21]}$ and 80 Gauss with a frequency of $2 \mathrm{~Hz}$ in another study. ${ }^{[22]}$ The intensity of PEMF might be a possible factor which could determine its efficacy. However, whether this could account for the discrepancy in the existing results still remains to be elucidated.

Review of the literature reveals no serious side effects related to the PEMF therapy. ${ }^{[9,23]}$ The side effects are usually mild including hypersensitivity rash, tingling, burning sensation, visual impairment, hypotension, and pain. None of the patients experienced any side effect with the PEMF therapy in the current study. The causes of discontinuation of treatment were difficulties in transportation to the clinic and unwillingness to continue. However, Sutbeyaz et al ${ }^{[8,12]}$ reported increased pain and low blood pressure as the causes of discontinuation of PEMF therapy in their studies. These side effects needed to be addressed, considering the relatively longer duration of therapy per session in that trial.

Nonetheless, there are some limitations to this study. First, in an ideal experimental trial setting to evaluate the effectiveness of PEMF therapy, patients would receive only magnetotherapy and sham magnetotherapy without concomitant physical therapy. However, such a setting would be problematic both from the ethical and clinical perspective. Hence, both the experimental and control (sham) group were to be given a conventional physical therapy program. Second, while patients were allowed to take paracetamol as necessary for pain reduction up to a maximum dose of $2 \mathrm{~g} /$ day throughout the treatment, the total dose intake was not recorded as a variable. Therefore, the possibility that paracetamol use might have been higher in the sham group and which reduced the difference between the groups remains unanswered. Other limitations include a lack of longterm outcome assessment, using outcome scales which are highly patient-dependent and subjective in nature and the heterogeneity of the patient group with respect to the etiology of neck pain. The latter might have limited the generalizability of the results.

In conclusion, the PEMF therapy is a safe treatment method in patients with chronic nonspecific neck pain. When applied as an adjunct to a conventional physical therapy program, PEMF therapy is not superior in improving pain and functional limitation. However, further large-scale, prospective, randomized-controlled studies using a standard dose of PEMF and a more specific patient sample would provide a firm evidence for its effectiveness.

\section{Declaration of conflicting interests}

The authors declared no conflicts of interest with respect to the authorship and/or publication of this article.

\section{Funding}

The authors received no financial support for the research and/or authorship of this article.

\section{REFERENCES}

1. Hoy DG, Protani M, De R, Buchbinder R. The epidemiology of neck pain. Best Pract Res Clin Rheumatol 2010;24:783-92.

2. Yamato TP, Saragiotto BT, Maher C. Therapeutic exercise for chronic non-specific neck pain: PEDro systematic review update. Br J Sports Med 2015;49:1350.

3. Yıldız M, Tuna H, Kokino S. Kronik Boyun Ağrılı Olgularda Spinal Mobilite, Ağrı ve Özürlülük İlişkisinin Değerlendirilmesi. Turk J Phys Med Rehab 2005;51:127-30.

4. Bruflat AK, Balter JE, McGuire D, Fethke NB, Maluf KS. Stress management as an adjunct to physical therapy for chronic neck pain. Phys Ther 2012;92:1348-59.

5. Sarig-Bahat H. Evidence for exercise therapy in mechanical neck disorders. Man Ther 2003;8:10-20.

6. Durmuş B. Servikal bölge sorunlarında egzersiz reçeteleme. Turk J Phys Med Rehab 2014;60:S15-S24

7. Markov MS. Expanding use of pulsed electromagnetic field therapies. Electromagn Biol Med 2007;26:257-74.

8. Sutbeyaz ST, Sezer N, Koseoglu BF. The effect of pulsed electromagnetic fields in the treatment of cervical osteoarthritis: a randomized, double-blind, shamcontrolled trial. Rheumatol Int 2006;26:320-4. 
9. Foley KT, Mroz TE, Arnold PM, Chandler HC Jr, Dixon RA, Girasole GJ, et al. Randomized, prospective, and controlled clinical trial of pulsed electromagnetic field stimulation for cervical fusion. Spine J 2008;8:436-42.

10. Bassett CA, Pawluk RJ, Pilla AA. Acceleration of fracture repair by electromagnetic fields. A surgically noninvasive method. Ann N Y Acad Sci 1974;238:242-62.

11. Alper S. Manyetik alan tedavisi. In: Beyazova M, editör. Fiziksel Tip ve Rehabilitasyon. Ankara: Güneş Kitapevi; 2011. s. 1075-83.

12. Sutbeyaz ST, Sezer N, Koseoglu F, Kibar S. Low-frequency pulsed electromagnetic field therapy in fibromyalgia: a randomized, double-blind, sham-controlled clinical study. Clin J Pain 2009;25:722-8.

13. Hattapoğlu E, Batmaz İ, Dilek B, Karakoç M, Em S, Çevik R. Efficiency of Pulsed Electromagnetic Fields on Pain, Disability, Anxiety, Depression, and Quality of Life in Patients With Cervical Disc Herniation: A Randomized Controlled Study. Turk J Med Sci 2019;49:1095-101.

14. Wheeler AH, Goolkasian P, Baird AC, Darden 2nd BV. Development of the neck pain and disability scale. Item analysis, face, and criterion-related validity. Spine (Phila $\mathrm{Pa}$ 1976) 1999;24:1290-4.

15. Aslan E, Karaduman A, Yakut Y, Aras B, Simsek IE, Yagli N. The Cultural Adaptation, Reliability and Validity of Neck Disability Index in Patients With Neck Pain: A Turkish Version Study. Spine (Phila Pa 1976) 2008;33:E362-5.
16. Ware Jr JE, Sherbourne CD. The MOS 36-item Short-Form Health Survey (SF-36). I. Conceptual Framework and Item Selection Med Care 1992;30:473-83.

17. Kocyigit H, Aydemir O, Fisek G, Memiş A. Kısa Form 36'nin Türkçe versiyonunun güvenilirligi ve geçerliliği. İlaç ve Tedavi Dergisi 1999;12:102-6.

18. Kroeling P, Gross A, Graham N, Burnie SJ, Szeto G, Goldsmith $\mathrm{CH}$, et al. Electrotherapy for neck pain. Cochrane Database Syst Rev 2013;8:CD004251.

19. Markov MS. Magnetic field therapy: a review. Electromagn Biol Med 2007;26:1-23.

20. Turan Y, Taştaban E. Magnetoterapi-magnetik akım tedavisi. Turkiye Klinikleri J PM\&R-Special Topics 2015;8:98-103.

21. Thomas AW, Graham K, Prato FS, McKay J, Forster PM, Moulin DE, et al. A randomized, double-blind, placebocontrolled clinical trial using a low-frequency magnetic field in the treatment of musculoskeletal chronic pain. Pain Res Manag 2007;12:249-58.

22. Turan Y, Bayraktar K, Kahvecioglu F, Tastaban E, Aydin E, Kurt Omurlu I, et al. Is magnetotherapy applied to bilateral hips effective in ankylosing spondylitis patients? A randomized, double-blind, controlled study. Rheumatol Int 2014;34:357-65.

23. Zwolińska J, Gąsior M, Śnieżek E, Kwolek A. The use of magnetic fields in treatment of patients with rheumatoid arthritis. Review of the literature. Reumatologia 2016;54:201-6. 